\title{
Mechanical Characterization of Fiber Reinforced Polymer Concrete
}

\author{
João Marciano Laredo dos Reis* \\ Programa de Pós-Graduação em Engenharia Mecânica, \\ Laboratório de Mecânica Teórica e Aplicada - LMTA, Universidade Federal Fluminense - UFF, \\ Rua Passo da Pátria, 156, Niterói - RJ, Brazil
}

Received: February 16, 2005; Revised: July 31, 2005

\begin{abstract}
A comparative study between epoxy Polymer Concrete plain, reinforced with carbon and glass fibers and commercial concrete mixes was made. The fibers are $6 \mathrm{~mm}$ long and the fiber content was $2 \%$ and $1 \%$, respectively, in mass. Compressive tests were performed at room temperature and load $v s$. displacement curves were plotted up to failure. The carbon and glass fibers reinforcement were randomly dispersed into the matrix of polymer concrete. An increase in compressive properties was observed as function of reinforcement. The comparison also showed that Polymer Concrete, plain and reinforced, has a better performance than regular market concrete, suggesting that $\mathrm{PC}$ is a reliable alternative for construction industry.
\end{abstract}

Keywords: polymer concrete, carbon fiber, glass fiber, compressive strength

\section{Introduction}

Concrete and steel were always considered the most important, and the most commonly used structural materials. The development of new high-performance composite materials that are stronger and more durable than conventional materials (e.g., Portland cement concrete, steel, wood, and masonry) is important to the construction industry ${ }^{1}$.

The use of concrete in the construction is very old. The first concrete used in history is reported to the Greeks and Romans times. In 1756, John Sweaton, in order to rebuild an important monument (Eddystone Lighthouse), developed the first mortar. "Portland Cement" appeared more less one hundred years later. Its name was given due to the resemblance of the color and quality of the hardened cement to Portland stone.

Synthetic polymers revolutionized the way new material was produced and made possible to produce cheaper and more flexible materials. Combining organic compounds at room temperature made possible the development of polymer-based materials, with a wide variety of properties ${ }^{12}$. Nowadays, other materials can also be added or blended. New polymers with almost any desired properties could be developed. It is therefore possible to design the best material for any given application ${ }^{2}$.

Polymer Concrete (PC) is a composite material formed by combining mineral aggregates such as sand or gravel with a monomer. Rapid-setting organic polymers are used in PC as binders. Studies on epoxy polymers have shown that curing method, temperature and strain rate influences the strength and stress-strain relationships ${ }^{13}$. The composition of PC is determined by its applications especially loading stress levels and ability to resist to corrosive environment. $\mathrm{PC}$ is increasingly being used as an alternative to cement concrete in many applications. For the past 50 years or more, the development of polymer concrete has been conducted in various countries. Today polymer concrete is used for finishing work in cast-in-place applications, precast products ${ }^{3}$, highway pavements, bridge decks, waste water pipes and even decorative construction panels. PC exhibits a brittle failure and therefore improving its post-peak stress-strain behavior is important. Hence developing better PC systems and also characterizing the compressive strength in terms of constituents are essential for the efficient utilization of PC. In order to improve the compressive behavior carbon and glass fibers can be added to the PC matrix. Substantial experience and broader knowledge of the optimal compositions $^{4}$, properties and stress-strain relationships of the fiber reinforced PC is necessary with respect to design, production and quality control. However, the data on epoxy PC are rather limited, and there is an increasing interest in the deformation characteristics under working conditions.

In this study, compressive properties of fiber reinforced epoxy polymer concrete are investigated at room temperature and compared with Commercial concretes from DEGUSSA ${ }^{\circledR}$ and HAGEN ${ }^{\circledR}$. The influence of fiber reinforcement with glass and carbon is also investigated.

DEGUSSA $^{\circledR}$ products compared were MASTERFLOW ${ }^{\circledR} 211$ and EMACO $^{\circledR}$ S88 and the products from HAGEN ${ }^{\circledR}$ were GROUTEK $^{\circledR}$ $S$ and HAGENPOX ${ }^{\circledast}$.

All these products have similar application as the polymer concrete under study, i.e. repairing of concrete structures.

\section{Experimental Program}

Previous studies done by researchers ${ }^{6}$, considering an extensive experimental program supported by the Taguchi method, allowed an optimization of polymer concrete formulations that are now being used in the present work.

Polymer concrete formulations were prepared by mixing foundry sand with an epoxy resin. Resin content was $20 \%$ in mass and no filler was added in both formulations. The epoxy resin system was eposil 551 (Silicem $\left.{ }^{\circledR}\right)$, based on a diglycidyl-ether of bisphenol A and an aliphatic amine hardener. This system has low viscosity, and is processed with a maximum mix ratio to hardener of $2: 1$. Fiber reinforced epoxy polymer concrete were prepared in the same way as plain epoxy polymer concrete, with the incorporation of $1 \%$ and $2 \%$ in mass of chopped glass and carbon fibers, respectively. The use of the specific percentage of reinforcement is followed based on the previous studies by the authors ${ }^{7,8}$.

Foundry sand used in this study was a siliceous one, with very uniform grain and a mean diameter, $\mathrm{d}_{50}$, of $245 \mu \mathrm{m}$. The sand was 
dried before added to polymeric resin in an automatic mixer. The chopped carbon fiber used has an epoxy sizing of $1.3 \%$, and the chopped glass fibers with no sizing and soaked in a 2\% silane A174 aqueous solution. The Silane coupling agent $(\gamma$-methacryloxypropyltrimethoxysilane, $\gamma$-MPS) was introduced by pre-treatment of glass fibers. The trimetoxy group undergoes hydrolysis in aqueous solution and hydroxyl groups are then available to form oxane bonds to the fiber surface. All chopped fibers considered were $6 \mathrm{~mm}$ length. The mechanical and chemical properties of the materials used to manufacture Polymer Concrete are presented in Table 1 and 2.

With these binder formulations and mix proportions, polymer mortars were mixed and molded to cylindrical specimens $(\phi 50 \times 100 \mathrm{~mm})$, as illustrated in Figure 1, according to the RILEM standard PC-2 ${ }^{9}$. For each formulation, three cylindrical specimens were cast. All polymer concrete specimens were allowed to cure for 7 days at room temperature and then post-cured at $70{ }^{\circ} \mathrm{C}$ for 3 hours, before being tested in compression.

Table 1. Thermal and mechanical properties of epoxy resin.

\begin{tabular}{lc}
\hline \multicolumn{1}{c}{ Resin properties (After one week at $25^{\circ} \mathrm{C}$ ) } & Epoxy Resin \\
\hline Glass transition temperature - DMA ( iso 6721-5) & $45^{\circ} \mathrm{C}$ \\
Heat distortion temperature - HDT ( iso 75) & $34{ }^{\circ} \mathrm{C}$ \\
Modulus of Elasticity - E (tension) (ISO 527) & $2.2 \mathrm{GPa}$ \\
Poisson's Ratio - v (ASTM C469) & 0.259 \\
Tear Strength ${ }^{\mathrm{a}}$ (iso 527) & $40 \mathrm{MPa}$ \\
Flexural Strength $^{\mathrm{a}}$ (iso 178) & $70 \mathrm{MPa}$ \\
\hline
\end{tabular}

${ }^{a}$ Mechanical properties given by the supplier.

Table 2. Thermal and mechanical properties of Glass and Carbon fibers.

\begin{tabular}{llc}
\hline \multicolumn{1}{c}{ Fiber Properties } & Glass Fiber & Carbon Fiber \\
\hline Density $\left(\mathrm{g} / \mathrm{m}^{3}\right)$ & 2.59 & 1.77 \\
Tensile Strength $(\mathrm{MPa})$ & $1380-2070$ & 3950 \\
Tensile Modulus $(\mathrm{GPa})$ & 72.45 & 238 \\
Linear Coefficient of Thermal & $5.0-6.0$ & -0.1 \\
Expansion $\left(10^{-6} / \mathrm{K}\right)$ & & \\
Elongation at break $(\%)$ & $3-4$ & 1.5 \\
\hline
\end{tabular}

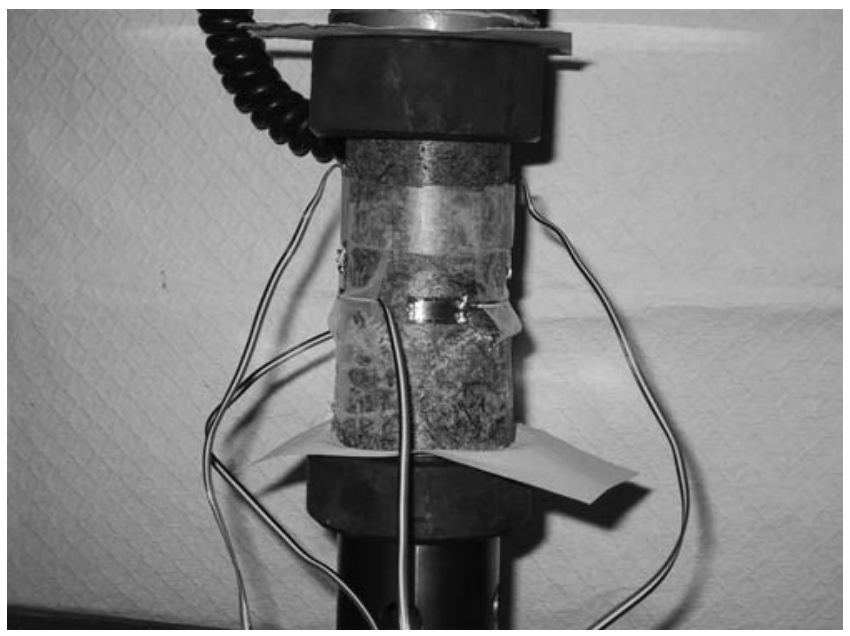

Figure 1. Compressive test specimens of Carbon fiber.
The commercial concretes used for comparison were manufactured according to the specification given by the manufacturer. Capping specimens were done with sulfur according to ASTM C617-98 ${ }^{10}$; to obtain top and bottom parallel faces a specific device shown in Figure 2 was used.

The compressive tests were performed using constant loading rate of $1.25 \mathrm{~mm} / \mathrm{min}$ according to ASTM C469-94 ${ }^{11}$. In order to obtain Poisson's ratio, one specimen of each batch was also instrumented
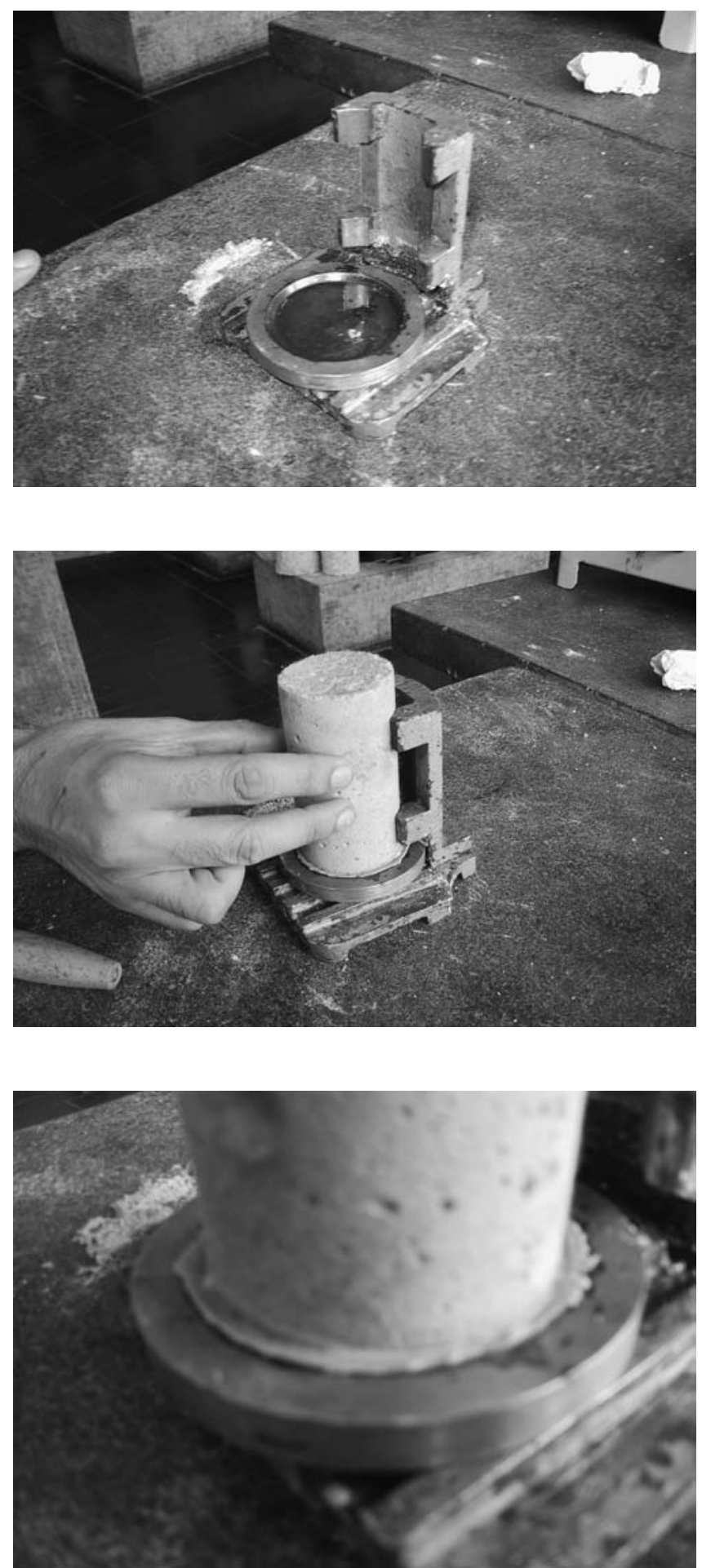

Figure 2. Capping cylinder specimens. 
with two-bonded strain gages mounted circumferentially at diametrically opposite points at the specimen mid-height. Longitudinal and circumferential strains were recorded continuously using a data logger with a continuous acquisition system. Compressive strength, chord modulus of elasticity in compression and Poisson's ratio were calculated using the following equations ${ }^{11}$ :

$$
\sigma_{C}=\frac{F}{A}
$$

where, $\sigma_{\mathrm{C}}$ is the compressive strength; $\mathrm{P}$ is the maximum load recorded; and A is the cross-sectional area of cylinder specimens ${ }^{11}$.

$$
E=\frac{S_{2}-S_{1}}{\varepsilon_{2}-0.000050}
$$

where $\mathrm{E}$ is the chord elasticity modulus; $\mathrm{S}_{2}$ is the stress corresponding to $40 \%$ of maximum load; $S_{1}$ is the stress corresponding to a longitudinal strain of 50 millionths; and $\varepsilon_{2}$ is the longitudinal strain produced by $\mathrm{S}_{2}{ }^{11}$.

$$
\nu=\frac{\varepsilon_{t 2}-\varepsilon_{t 1}}{\varepsilon_{2}-0.000050}
$$

where $v$ is the Poisson's ratio; and $\varepsilon_{\mathrm{t} 2}$ and $\varepsilon_{\mathrm{t} 1}$ are the transverse strains at mid height of the specimen produced, respectively, by stresses $\mathrm{S}_{2}$ and $S_{1}{ }^{11}$.

\section{Test Results and Discussion}

The specimens after testing are presented in Figures 3 and 4. Mechanical properties obtained from compressive tests performed on fiber reinforced epoxy polymer concrete and commercial concretes found in the market are presented in Table 3. The results presented in Table 3 show that fiber reinforcement improves the compressive strength of epoxy polymer concrete. While carbon fiber reinforcement shows an improvement by $16 \%$ in the compressive strength, only $8.7 \%$ increase improvement is observed for glass fiber reinforcement. The behavior is different when elastic modulus is analyzed. Both carbon fiber reinforcement and glass fiber reinforcements do not improve the compressive elastic modulus of the composites; in fact, a slight decrease is observed in carbon fiber reinforced composite. On the other hand, the values of Poisson's ratio do not show a clear trend. The random distribution of fibers means that anisotropic feature has its value averaged through all possible orientations.

There is a slight difference between the test results, due to random distribution of fibers.

When compared to commercial concretes, plain epoxy concrete exhibits higher compressive strength values ranging from 17.3 to $33.7 \%$. Similarly, compressive strength values of glass fiber reinforced composite are higher in the range of 27.5 to $45.4 \%$, while carbon fiber reinforced epoxy polymer concretes showed even more higher values ranging between 36.1 to $55.1 \%$.

Table 3. Compressive Properties of Plain, Fiber Reinforced Polymer Concrete and Commercial Concretes.

\begin{tabular}{lccc}
\hline \multirow{2}{*}{ Test Series } & \multicolumn{3}{c}{ Compressive Properties (Average) } \\
& $\begin{array}{c}\text { Strength } \\
(\mathrm{MPa})\end{array}$ & $\begin{array}{c}\text { Elastic. Modulus } \\
(\mathrm{GPa})\end{array}$ & $\begin{array}{c}\text { Poisson's } \\
\text { Ratio }\end{array}$ \\
\hline Plain & 59.681 & 11.281 & 0.259 \\
CFRPC & 69.215 & 10.882 & 0.247 \\
GFRPC & 64.873 & 11.551 & 0.257 \\
MASTERFLOW 211 & 50.862 & - & - \\
EMACO S88 & 45.118 & - & - \\
GROUTEK S & 44.618 & - & - \\
HAGENPOX & 49.697 & - & - \\
\hline
\end{tabular}

\section{Conclusions}

The following conclusions can be drawn concerning the properties of fiber reinforced polymer concrete formulations considered in this work:
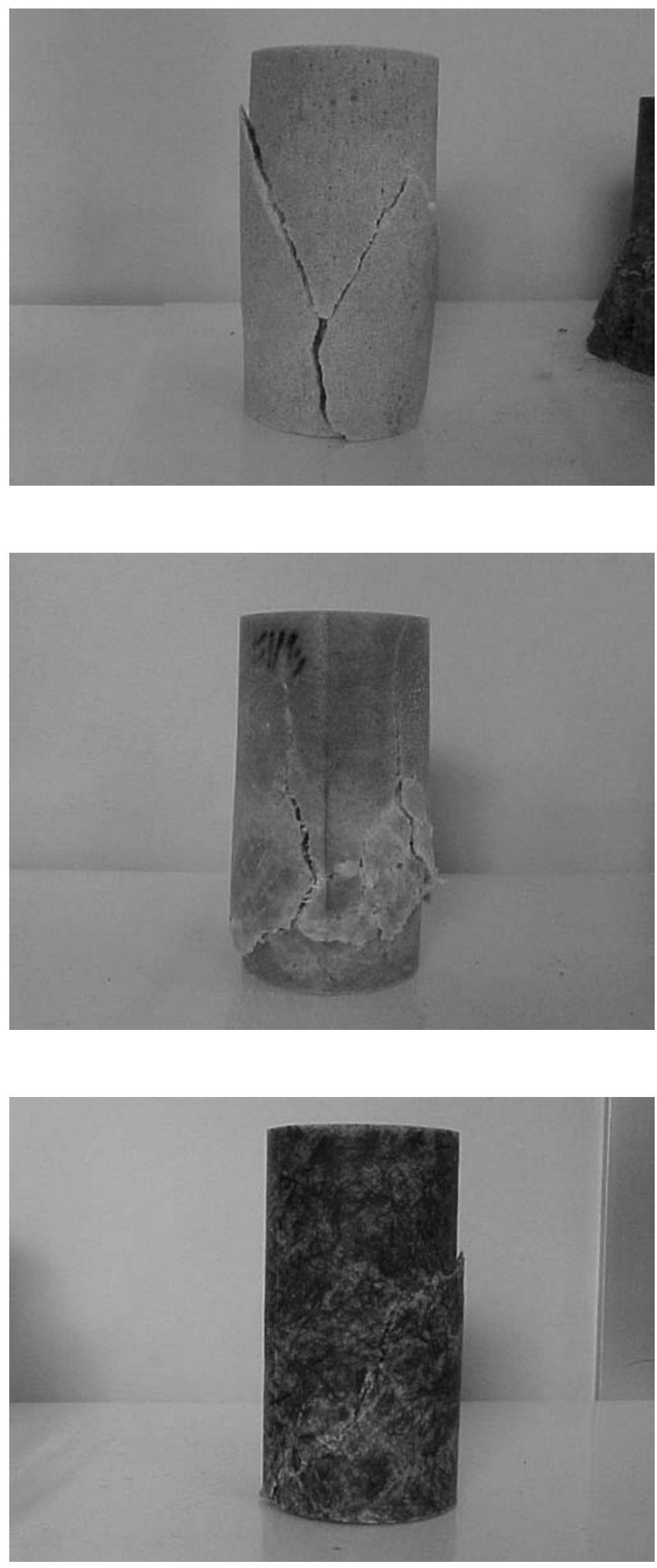

Figure 3. Epoxy, Glass and Carbon Fiber Polymer Concrete Specimens after Testing. 

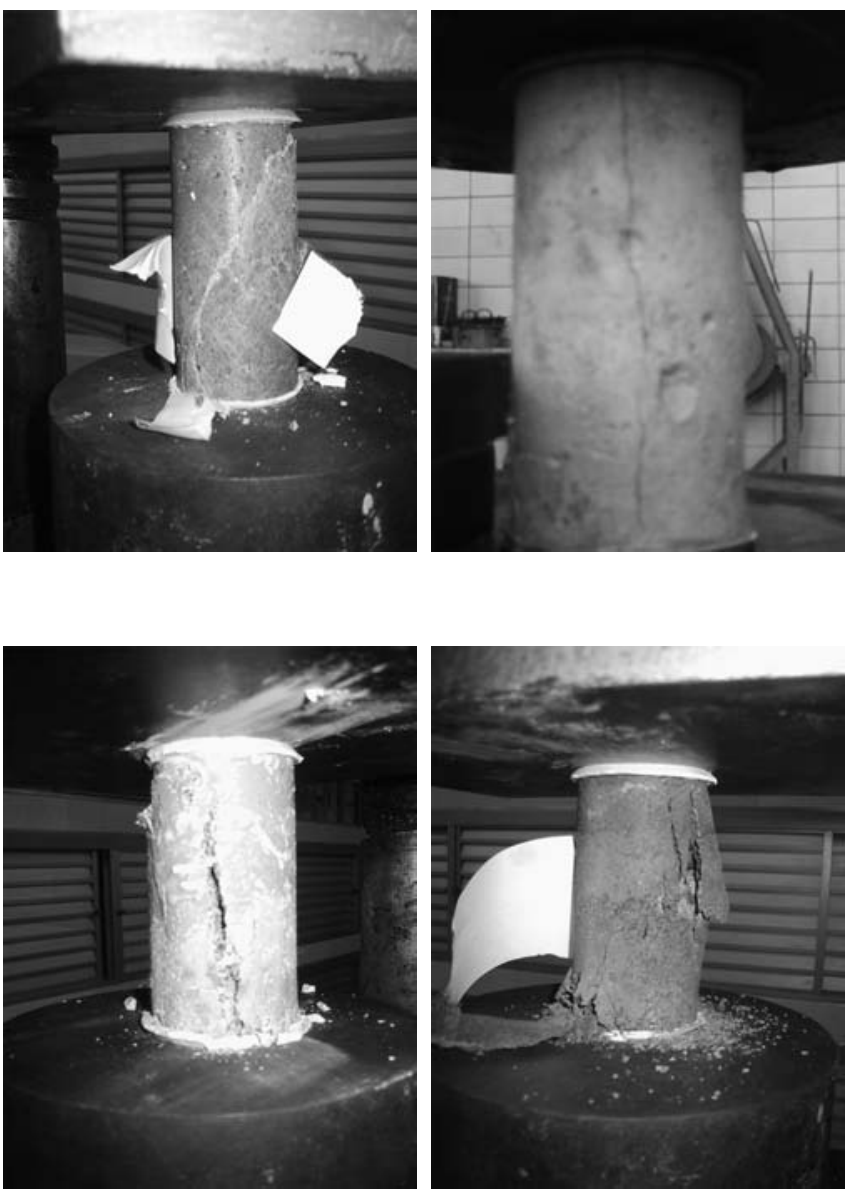

Figure 4. Commercial Concretes under testing. Materflow 211, Emaco S88, GroutekS and HagenPox, respectively.

- As expected, carbon and glass fibers reinforcements affect the strength of epoxy polymer. For the formulations studied, a considerable improvement in compressive strength [27.5 to $45.4 \%$ for glass fiber composite and 36.1 to $55.1 \%$ for carbon fiber composite over that of the matrix] is observed;

- Similarly, failure behavior of the polymer matrix is altered by fiber reinforcement, resulting in a slightly ductile failure, while unreinforced polymer concrete shows a brittle failure;

- The mechanical properties of fiber reinforced polymer concrete observed in this study are higher compared to ordinary cement concrete. Comparing plain polymer concrete to ordinary concrete, compressive strength is $85 \%$ higher $^{14}$. When
Polymer concrete is reinforced, increase higher than $100 \%$ is observed; and

- Epoxy Polymer Concrete in both forms [with and without fiber reinforcement] proved to be an excellent alternative to concretes available in the market.

The above results suggest that fiber reinforcement is a good choice to improve mechanical properties of polymer concrete, opening a door for more practical and representative applications including reinforcement of commercial concrete.

\section{References}

1. Rebeiz KS, Fowler DW. Flexural Strength Reinforced Polymer Concrete Made with Recycled Plastic Waste, ACI Structural Journal. 1996; 93(5):524-530.

2. Cano M, San Jose JT, Ramyrez JL. Polyester polymer concrete: fundamental hardened and fresh state. Proceedings of the Second Conference International sur les Materiaux Composites en Architecture, Construction et Genie Civil, Bordeaux, France, 1998.

3. Ohama Y. Recent Progress in Concrete-Polymer Composites. Advanced Cement Based Materials. 1997; 5(2):31-40.

4. Ribeiro MCS, Tavares CML, Figueiredo M, Fernandes AA, Ferreira AJM. Bending characteristics of resin concretes. Materials Research. 2003; 6(2):247-254

5. Vipulanandan C, Paul E. Mechanical Properties of Epoxy and Polyester Polymers and Polymer Concrete Systems. Report no UHCE 88-13, University of Houston, 1988.

6. Ferreira AJM, Tavares CML, Ribeiro MCS. Flexural properties of polyester resin concretes. Journal of Polymer Engineering. 2000; 20(6):459-468.

7. Reis JML, Ferreira AJM. Fracture Behavior of Glass Fiber Reinforced Polymer Concrete. Polymer Testing. 2003; 22(2):149-153.

8. Reis JML, Ferreira AJM. Assessment of fracture properties of epoxy polymer concrete reinforced with short carbon and glass fibers. Construction and Building Materials. 2004; 18(7):523-528.

9. PC-2. Method of Making Polymer Concrete and Mortar SpecimensRILEM- Technical Committee TC-113. Bélgica, 1995.

10. ASTM C617-98. Standard Practice for Capping Cylindrical Concrete Specimens. USA, 1998.

11. ASTM C469-94. Standard Test Method for Static Modulus of Elasticity and Poisson's Ratio of Concrete in Compression. 1994.

12. Nielsen LE. Mechanical Properties of Polymers and Composites, Vol.2, New York: Marcel Dekker Inc., 1974.

13. Vipulanandan C, Dharmarajan N, Ching E. Mechanical Behaviour of Polymer Concrete Systems. Materials and Structures, Research and Testing. 1988; 21(24):268-277.

14. Berthet J F, Ferrier E, Hamelin P. Compressive behavior of concrete externally confined by composite jackets. Part A: experimental study. Construction and Building Materials. 2005; 19:223-232. 